\title{
Stability and plasticity in self-organized networks
}

\author{
ChRISTOPHE ASSENS*
}

\begin{abstract}
Despite some research on self-management and self-organization, the control and the coordination of an organization without hierarchy remains a mysterious phenomenon. However, the dissemination of the responsibilities and the decentralized decisions in a business network require improving our knowledge in this field. From this theoretical point of view, our article aims to explore the modes of development and regulation of the networks not supervised. After having underlined the difficulties of empirical observation at the origin of the modeling attempts, we put forward the idea according to which a network without pilot is pulled about two tensions: stability and plasticity. Indeed, to mitigate the problems of internal coherence, it is led to evolve towards a more stable form and thus more hierarchical. But, in the absence of central coordination unit, it is also directed towards a more unstable form, based on the flexibility of the embedded connections.
\end{abstract}

Classification Codes: M10.

\section{Introduction}

According to Aristotelian logic (384-322 before J.-C.), many researchers attempted to study the social organization with a positivist perspective which admits universality of the laws, the separation of the studied object and the observer (Chalmers, 1987), the links of cause for purpose to explain the empirical phenomena. These epistemological postulates allow to describe an industrial firm with some immutable principles: the establishment of a strategy which precedes or which rises from the structures, the role of an executive which supervises the strategy process by the inputs with the planning procedure and/or by the outputs with the accounting rules, the strategy results which depend on external influences or internal contingencies.

Since a few years, these great principles of research in strategy and management are supplemented by new projections on the epistemological level: the difficulty in separating the researcher from his subject, because this one by its presence disturbs the observed phenomena (Susman and Evered, 1978), the difficulty to analyze an organizational

\footnotetext{
* IUT d'Évreux, Département Techniques de Commercialisation, 55, Rue Saint-Germain, 27000 Évreux, France. E-mail: assens @ club-internet.fr; Home page: http://perso.club-internet.fr/assens

Keywords: Network, dynamics, self organization, stability, plasticity.
} 
dynamic through sequential events because of anticipations and feed-backs occurrences (Lussato, 1992), the absence of universality in management because of organizational differences in history (Fridenson, 1993), culture (D'Iribarne, 1989) and identity (Broustail, 1992a). These observations facilitated the emergence of the constructivist paradigm (Bouchikhi, 1991) in shift with the positivist paradigm.

This evolution in the way of apprehending the social organization introduced new theories, like systemic model (Durand, 1979) or the chaos theory (Thietart and Forgues, 1995). New subjects of investigation take into account the instability of the company confronted with the crisis management or the change governance. Moreover, new methods of social modeling conceive the complexity of these phenomena, with genetic algorithms (Weisbuch, 1989) resulting from the analysis of the neural network (Aurifeille, 1994).

These new theoretical projections call in question a representation of the company inherited from Fayol (1949) or Taylor (1916) where prevails a unity between command, time and place of production. Indeed, even if there are firms governed on these traditional postulates, more complex organizations appear according to Daft and Lewin (1993):

- organizations which break with the traditional concept of bureaucratic control;

- structures which are based on complementary relations between autonomous decisionmaking centers;

- organizations whose borders escape the usual criteria from authority or property (Weiss, 1994).

Under the effect of the markets globalization and the rise of strategic alliances which result from this situation (Osborn and Hagedoorn, 1997), a great number of companies work in partnership under the influence of multiple hierarchical centers. Certain of this exchanges give rise to business networks when, according to Thorelli (1986), the corporate transactions are held in a recurring way, to constitute a stable relational structure apart from the market or hierarchy model.

Thus, the term of network includes various situations. Initially, it relates to the externalization process engaged by big companies to reduce production costs and to cope with their rigid hierarchical system (Bartlett and Ghoshal, 1993). In this field, we can mention the examples of Nike, Benetton, ABB (Kennedy, 1992) ${ }^{1}$ or Lafarge-Coppee ${ }^{2}$. At the same period, a great number of researches relate phenomena of alliances and cooperation

\footnotetext{
${ }^{1}$ A.B.B (Asean Brown Bovery) is one of the world giant in the equipment sector. Resulting from the fusion of two complementary industrial sets, its president Percy Barnevik considered as essential to privilege an autonomy of local decision in the respect of a global coherence. In the Nineties, its credo "think global and act local" gives rise to the creation of a network of 1300 small businesses subdivided in 5000 profit centers, established in 140 countries.

${ }^{2}$ For a long time, Lafarge Coopee tries out the network form of organization to induce more local initiative and implication while reducing global complexity, according to one of its leaders: "this quite naturally resulted in affirming how much it is significant that each one feels the peremptory necessity to make live horizontally and diagonally the flow chart by personal relationships with double direction which does not hold any account of the hierarchical positions".
} 
between firms. The concept of network then includes durable forms of cooperation which escape from contractual rules or hierarchical agreement (Baker, 1990).

Identified in Japan under the term of "Keiretsu" (Gerlach, 1992), this type of partnership takes the shape of technological valley or industrial districts in Europe (Camuffo, and Costa, 1993). From these observations, several remarks can be made:

- A network is founded on durable and informal relations between the members. Those are established on the basis of mutual trust (Raub and Weesie, 1990) which does not result from the application of directives, nor of the execution of instructions or the implementation of procedures.

- The relations between the members are not inevitably settled on a hierarchical basis. Thus in the self-organized network, there is not a unique decision center (pilot), but as many decision centers than the entities to form part of it.

- These relations lie within the scope of a self-regulation process, similar to the creation of a collective order from the disorder of individual interactions, specific to the dynamics systems (Thom, 1981).

For this reason, the network is neither a collection of individuals isolated on a market, nor a set of indissociable units integrated in a single company (Butera, 1991). To understand the networking, various cases should be distinguished. In certain situations, one or several pilots supervise the relations between the units' members of the network (Lorenzoni and Baden Fuller, 1993); in other contexts, the members coordinate their actions without depending on a collective authority (Drazin and Sandelands, 1992). Notable fact, the absence of pilot or the lack of hierarchy does not put back the networking efficacy.

Indeed, the network with autonomous dynamics indicates an organization deprived of center, and whose operation concerns the principles of self-organization (Nonaka, 1988). Consequently, the local interactions process between the units has a considerable importance to understand the functioning of the organization. Thus, the order or the disorder within the network does not result from the implementation of procedures or the application of directives, but from a free cooperation founded on conventions which are not imposed by one partner only (Assens et al., 2000). In the self-organized network, there is not a single decision-making center, but as many decision-making centers than of entities. Then, no member is able to have an overall vision and control of the connections in this organization.

However, the coherence seems preserved by "exchange rules" or by trust atmosphere which compensate the absence of hierarchical regulation. These rules often present an informal character (Hanson and Krackhardt, 1993). They survive as the relations intensify and as the experiment increases between the members.

On the one hand, the network configuration appears as the result of self-regulation process which emerges from the interactions between the units. Under these particular conditions, this mode of organization appears chaotic and disordered for certain authors (Miles and Snow, 1992). So, the fragmentation of the decision-making centers and the absence of central coordinator seem to harm the network development. That is explained mainly by the political game and the conflicts of power during individual interactions. According to Crozier and Friedberg (1977), the lack of formalized context in this social model focused on the autonomy of the actors is prejudicial to the consensus. Then, the 
specialization of competencies becomes inevitable to survive in the structure, as a source of competition, isolation or dispersal.

On the other hand, other authors (Nonaka, 1988; Stacey, 1995) highlight the emergence of a collective order despite the dissemination of individual decision-making centers, because of the knowledge sharing, the federation of assets and the exchanges reciprocity in a climate of trust (Lomi, 1999). To exceed this controversy, we will study the evolution of self-organized networks under the theoretical dimension (first part), and under the empirical dimension with efforts of modeling (second part). After having defined the field of research, we will show that the networks without pilot are permanently confronted with the dilemma of stability-plasticity: the integration of the ramifications in a rigid and stable net, or the differentiation of the ramifications in a net open to variety and instability.

Locally, the network members seek to preserve their autonomy so as to adapt to specificity of their environment. Then, the networking privileges a great structural flexibility which results in the emergence of unplanned connections, and by the growth of local initiatives (Assens, 1997). In situations of tension or conflict, this individual liberty of action can go against the collective stakes by causing a strong failure (Dörner, 1989). So, by privileging their capacity of adaptation, the members avoid standardizing their relations, without worrying about the inconsistencies. On the contrary, if the principle of cohesion becomes a main priority, the flexibility of the units is likely to be attenuated. As a result, the network could then evolve to an integrating model more hierarchical.

\section{Theoretical foundations}

\subsection{The evolutionist theories}

According to Stacey (1995), there are two evolutionist approaches in the theory of organizations. The first stresses the concept of rational and intentional strategic choice (March and Simon, 1958). Opposed to this vision, another approach tends to privilege the organizational transformations in regard to the constraints imposed by the environment (Boyd, 1990). In the search for suitability to its environment, the organization is then perceived as an open system which adapts to the exogenous (natural selection) ${ }^{3}$ or endogenous constraints. Two large currents summarize these ideas: macro determinism and micro determinism.

\footnotetext{
${ }^{3}$ The principle of natural selection in the ecology of the populations (Hannan and Freeman, 1977) or the resources dependency (Pfeffer and Salancik, 1978) is inherited from the thought of Darwin (1949). This one explains why all the visible differences between biological species are the reflection of a natural selection process, supporting the development of specialized functions: "the species sustain the change, and the forms of existing lives are the descendants by true generation of preexistent forms... it was that I read by entertainment on the Malthus's Population and, being well prepared to appreciate the fight for the existence, and the idea struck me that, in these circumstances, favorable variations would tend to being preserved, and that others variations less privileged would be destroyed. The result of this would be the formation of new species".
} 


\subsubsection{Macro determinism}

This prospect is centered on the analysis of the exogenous causal forces, defined by the resources based theory (Pfeffer and Salancik, 1978) or by the transaction costs theory (Williamson, 1983). So, the strategies and the structure of each company must fit to the nature of the environment. One of the most known examples of this determinism relates to the theory of Hannan and Freeman (1977) on the ecology of the populations. The organizational structure appears then as the best form adapted during a process of "natural selection" to survive within a branch of industry.

\subsubsection{Micro determinism}

Certain scholars assign the origin of the structural evolution to the strategic decisions. According to Gomez and Probst (1987) the decision-making would shape directly the structure in conformity with strategic choices.

On the same plan, Chandler (1962) shows from an historical study that the evolution of the structures depends on the strategic decisions taken by the managers.

These deterministic theories stress external factors which escape from human control, or which rely on internal objectives specific to individuals characterized by limited rationality (Simon, 1957). However, these theories are unsuited to our object of study (the network with autonomous dynamics) because they presuppose two essential aspects: the very clear distinction between the organization and the environment, an authority center clearly identified.

The extensive ramification of the network does not effectively allow an obvious separation between the organization and its environment. In the exchanges between the units, it becomes increasingly difficult according to Weiss (1994), to trace frontier lines of demarcation. The network members are not necessarily related to the same shareholder; the borders thus escape the criterion from property, but they also escape the limits from the traditional flow charts (Hanson and Krackardt, 1993), insofar as the exchanges neither are classified on a hierarchical basis nor divided by geographical area or trade. Under these conditions, it appears difficult to explain the evolution of the network only by taking into account the influence of the environment, as in the populations ecology with competitive selection. In the same way, it seems abusive to interpret the changes, only, like the fruit of an intentional strategy shared by a common agreement through the members.

On the contrary, by admitting the distribution of power within the net, we accept the idea of an unstable dynamics founded to some extent on the absence of consensus, because of the conflicts between individual interests (Astley and Zajac, 1991). The order which results from it, emerges then from these conflicts and not from a supra authority which would represent the collective responsibility.

\subsection{The theories of complexity}

From the limits of the evolutionary theories, it is appropriate to evoke the sciences of complexity like the chaos theory (Thietart and Forgues, 1993), the systemic logic (Le Moigne and Jameux, 1990) or the connectionism foundations (Davalo and Naim, 
1989). Indeed, these approaches are better fitted to the case of complex organizations like the networks without pilot:

- Organizations made ungovernable by the increasing number of elements and relations between them. This characteristic requires paying our attention on the effects of decentralization by studying the dissemination of the elementary decision-making centers.

- Organizations made unverifiable because of the absence of objective criteria allowing to evaluate and compare multiple purposes on the individual and collective level, whose logic's are opposed and complementary at the same time. This co-determination of the whole and the parts requires adopting two levels of analysis simultaneously: the local and the global level (Morin, 1985).

- Organizations whose development is discontinued and not linear, i.e. comprising phenomena of retroaction, anticipation and feedback which introduce a temporal dimension into the analysis. That forces to adopt a longitudinal perspective by stressing the initial conditions (Crozier and Friedberg, 1977).

- Organizations finally, whose finalities rely on the initial conditions, which depend themselves on the required purposes. The confusion between causes and effects then obliges to reflect on the interactions processes between the elementary decisionmaking centers, rather than on static analysis about competencies or intangible assets (Pettigrew, 1990).

Several authors such as Freedman (1992), Daft and Weick (1984) or Stacey (1995) highlighted the complex nature from some organizations. The learning company ${ }^{4}$ of Freedman (1992), the cognitive representations system of Daft and Weick (1984) or the self-organized concept of Drazin and Sandelands (1992) falls under this viewpoint. This type of organization is auto-piloted. The rules of activation and learning allow distributing the decisional capacity on the whole members, without being subjected to the influence of a central unit of regulation. The members communicate gradually in order to sustain the reciprocal relations which support the collective learning and memorizing. Among the theoretical approaches of complexity, one of them is particularly adapted to the case of the networks with autonomous dynamics. It is the connectionism based on the observation of neural networks.

\subsection{The connectionist theories}

Since the invention of data processing, the human being wants to deliver an intelligent machine. Therefore, the best example of not programmed adaptation lies in the human brain. From this report, many researchers are learning on the study of the neural network. The first modeling dates from the Forties. Starting from Mc Culloch and Pitts's work in 1943, the brain is perceived as a logical machine whose activity seems to be from a

\footnotetext{
4 "The learning organization has characteristics remarkably similar to the complex adaptative system that scientist are discovering in nature. It is highly decentralized system in which any number of decision making processes on the local level maintain order throughout and constantly adjust to changes. In effect, the learning organization replicate the organic control found in nature" according to Freedman (1992).
} 
binary type; in other words neurons are either "activated" or "inactivated". They transmit or block information.

On the basis of this theoretical postulate, other scientists as von Neuman and Morgenstern (1947) work out models without biological substrate. The principle of the artificial networks then consists in reproducing the activation of the neurons considered as simple processors in the transmission of information by means of the synaptic connections. As from this time, the brain ${ }^{5}$ is modeled in the shape of a binary machine, whose elements transmit or do not transmit information in accordance with activation thresholds.

A multidisciplinary current was established from this modeling. It is called the "connectionism" whose repercussions relate to data processing, cognitive sciences, artificial intelligence, robotics, the signal treatment in medical imagery, etc. But this current meets especially a renewed interest in management sciences (Davalo and Naim, 1989). The connectionist approach indeed makes it possible to conceive methods of very powerful data analysis (Aurifeille, 1994): methods of "scoring" more precise than the techniques of linear discriminating analysis; methods of multicriterion analysis richer than the methods of factorial analysis (analyzes in principal components); techniques of classification more efficient than the usual methods of segmentation by the regression analysis.

The majority of these methods are founded on genetic algorithms ${ }^{6}$ which authorize forms of learning in the machines programming.

But, in complement of this methodological contribution, the connectionism introduces a grid of enriching reading to photograph the self-organized networks.

Therefore, the connectionist model reflects the properties of the networks of neuron functioning without pilot. For this reason, the connectionist model stresses the three

\footnotetext{
${ }^{5}$ The simplification of the human neurons operation made it possible to implement numerical technology starting from microprocessors. Actually, the biological neurons are subjected to activations whose threshold of intensity varies between 1 and 100, well beyond the binary electric frequencies of the "electronic neurons". This is why certain researchers think to improve the performances of the current computers with the adoption of the biological microprocessor. But, the marriage between the man and the machine are especially most obvious in the new grafts of bodies controlled by microchips.

${ }^{6}$ The genetic algorithm corresponds to a new programming method able to make the machine more autonomous in the data processing for modeling, classification and correlation of items. Let us take the example of an algorithm charged to solve a quadratic equation: $x^{2}-3 x+2=0$. The principle of the genetic algorithm consists in creating a population of individuals (here whole numbers) which converges towards the solution of the equation by dichotomy and iteration. Thus, for each individual, one judges of their degree of adaptation to the solution in substituting the value of $x$ by the value of the individual observed. The value of the polynomial then is calculated; the closer this value is to the awaited result (here 0 ), the more the individual will be considered adapted. For example the individual $\mathrm{x}=3$ is adapted better than the individual $\mathrm{x}=5$. From this procedure, one determines a function of adaptation which allows to associate a note of evaluation to each individual. When all the individuals of a population of whole numbers were observed, one preserves only half of the individuals approaching the nearest from the solution, the others being removed from the population. Then, by mechanisms similar to those observed in genetics, one carries out crossings in the remaining population so as to find the number of initial individuals. One finds oneself then in the presence of a new generation of individuals engaged again in the process of selection. From a certain iteration count, the population converges towards a solution which one cannot know in advance. This technique tends to surpass the traditional methods of segmentation or classification.
} 
characteristics common to the not supervised networks: a net structure, a rule of activation and a rule of learning.

\subsubsection{The net structure}

The ramification structure is constituted by a set of nodes (indivisible cells, decisionmaking unit) connected by directed links or connections which inhibit or excite the relation. Taking into consideration this definition, Perez (1990) stresses the diversity of networks with autonomous dynamics. Those are characterized by nature from the nodes and the type of connection studied ${ }^{7}$.

By way of comparison, the net structure of the neurons in the human brain is asynchronous with parallel and random connections. Generally, the majority of the current neural networks are synchronous and most of the time with partial and random connections.

\subsubsection{The rule of activation}

The rule of activation in a connectionist model is a local procedure which governs the behavior of the nodes (cells). The level of activation of each node is interdependent with the activation of the closets nodes (two nodes directly connected by a link are known as neighbors) according to the same local procedure. The significant points defining a rule of activation relate to the parallelism of mass at the global level, and the character of transmission not standardized at the local level.

The parallelism of mass refers to a not sequential architecture within all the cells exert the same functions at the same time. According to this definition, the collective activity is divided into parallel on the whole set of the units, which will occasionally process the same data at the same moment as the others. This redundancy improves the capacities of the network to avoid the ruptures of connections or the nodes destruction which can involve for example losses of memory.

The local dimension of the data processed by each node is restricted with the information transmitted by the close nodes via connections. According to this description, the function of regulation is completely distributed at the local level. This property allows the network to increase its autonomy, while remaining coherent.

\subsubsection{The rule of learning}

In a connectionist model, the rule of learning indicates the inclination of a network to change behavior according to the achieved results and experiment. More precisely, a rule

\footnotetext{
${ }^{7}$ Perez (1990): "the cells (symbolic systems objects, data processing or memories zones) are connected between them in network. The network can be synchronous or asynchronous, with partial or total connections, random or monotonous connections. In a synchronous network, all the cells are activated at the same time; in an asynchronous network, each cell is activated in an autonomous way. Each cell can be connected only to some close cells (partial connections) or to the entire network (total connections). The regularity of the network can be random, each cell being connected randomly to other cells; or monotonous, each cell being connected, in a regular way to its four neighbors for example (proximity in checkerboard known from von Neuman and Morgenstern (1947)."
} 
of learning is a local procedure which describes how the weight of connections varies and influences the evolution of the nodes.

This procedure is subjected to the law of Hebb (1949): this law defines the conditions of relation reinforcement between two neurons which share mutual activities. In fact, the cooperation between two close cells creates an interface at the level of their connections. In other words, when two neurons are influenced in a repeated way, their connections modify their activities in the direction of a positive reinforcement of their links. On the contrary, it could exert a negative reinforcement of their link.

The rule of learning is either internal or external. When the network has the capacity to associate the shape of entry already learned to a form not learned at the exit but near from the initial form, we speak then about a learning process by retro propagation ${ }^{8}$. That means that the adjustment of the weights between the neurons is carried out by reflecting the variations noted at exit of the network on the transformations carried out upstream. The logic diagram learned by the neurons is then generalized with the rest of the structure during a process of neural-mimesis ${ }^{9}$.

This learning process must be correlated with the concept of associative memory defined by Kohonen (1988) and characterized by the matrix of the connections weight. This memory allows the network to permanently adapt to its environment in a flexible and local manner, without loosing total coherence (Le Moigne, 1989). We speak about associative memory when the recording of a concept is distributed on several neurons at the same time.

In other words, the property of memorizing depends less on specific competencies to each neuron than on arrangements between the neurons according to the order or the sequence of their relations (Changeux, 1983). By analogy, there is an identical phenomenon when an anagram is carried out. One forms two different words with the same letters. The significance of the word is not subjacent with the letters considered out of their context. On the contrary, it depends to their specific combination. Thus, the meaning of a word depends less on the nature of the letters than of their fitting.

To recapitulate, several postulates are common to the connectionist models. The data processing is parallel at all levels. In this way, each model is comparable with an autonomous system (Lorigny, 1992), in which the intelligence is an emergent global property from the many concurrent local interactions.

Davalo and Naim (1989) then speak about a "synergetic" network to underline this property of collective intelligence which emerges from local complementary between close nodes.

\footnotetext{
${ }^{8}$ The retropopagation is a phenomenon comparable with the process of feed back in the complex systems. In data-processing modeling, the principle consists for instance in minimizing the square of the differences between the awaited values and the values estimated at the exit. The variations are reflected step by step between neurons, from the exit of the network up to the starting points, by a rule of learning whose formula is comparable with a recurring continuation.

${ }^{9}$ The neural-mimesis is a phenomenon of mutual adjustment about the weight and influence of the neurons. By the set of connections, each neuron will adopt an attitude close to its immediate neighbors, until a stable attitude emerges to form a collective unity. It is the same principle which occurs in a concert hall, where the applause is harmonized on same rate to cause the recall of the artist.
} 
As Figure 1 underlines it, this model can be transposed to many cases of organizations: the neural network in neurobiology, the associative network of the mental map in cognitive science, the social network or the corporate network without pilot in organizational theory.

\begin{tabular}{|c|c|c|c|}
\hline & Neural network & Cognitive network & Social network \\
\hline Scientist fields & $\begin{array}{l}\text { biophysics } \\
\text { neurobiology }\end{array}$ & $\begin{array}{l}\text { cognitive psychology } \\
\text { (mental) }\end{array}$ & $\begin{array}{l}\text { cognitive } \\
\text { psychology } \\
\text { (behavioral) }\end{array}$ \\
\hline Node & neuron & concept & actor \\
\hline Connection & synapse & association & channel of communication \\
\hline Activation & $\begin{array}{l}\text { frequency of the potentials } \\
\text { of action }\end{array}$ & belief or probability & rules of communication \\
\hline $\begin{array}{l}\text { Type } \\
\text { of representation }\end{array}$ & $\begin{array}{l}\text { distributed } \\
\text { ( } 1 \text { concept for several nodes) }\end{array}$ & $\begin{array}{l}\text { local } \\
\text { (1 concept by node) }\end{array}$ & $\begin{array}{l}\text { divided } \\
\text { (several concepts by node) }\end{array}$ \\
\hline
\end{tabular}

Fig. 1. Networks with dynamic autonomous.

Each network with autonomous dynamics is characterized simultaneously by active elements of treatment (elements and connections), whose local interactions, while varying in time, define the global direction and regulation of the collective action. Consequently, the configuration of the organization emerges from the processes of exchanges between the autonomous elements. To understand the nature of these processes, it is then essential to indicate the evolution perspectives for these networks.

\section{Evolutionary modelling}

\subsection{The self-organization: Stability-plasticity}

For Drazin and Sandelands (1992), the evolution of networks with autonomous dynamics results from the self-regulation of the interactions ${ }^{10}$ between the elements. This self-regulation is based on tacit and conventional norms, which coordinate the behavior of the entities during their exchanges.

Under these circumstances, in the example of the neural network, each cell interacts with the cells located at proximity, following the activation rules which neither are supervised, nor programmed. In another context, that of the social organization, Semler

\footnotetext{
${ }^{10}$ For Watzlawick, Helmick Beavin and Jackson (1972), the interaction is a process which mobilizes at least two people. In this context, the interaction corresponds to the action of a person, the answer of another and the response of the response by the first. The interaction thus translates the degree of interdependence between the individuals.
} 
(1990) introduced the idea of a company without hierarchical framework. In this context, he highlighted the importance of self-management which guides the actors in their decision.

According to Bouchikhi and Kimberly (1992), these foundations of self-management are strongly inspired by the rules of life inside a clan, even if bureaucratic procedures still remain. According to these comments, the network with autonomous dynamics function in the absence of supervisor, by the help of behavioral codes which emerge in an informal way during interactions. By reinforcing the links between the individuals, these codes strengthen themselves with the habit or the tradition.

Deprived of the hierarchical references, this operating mode is strongly exposed at the risks of failure. Initially, the decisional autonomy of the actors cannot be exerted fully because of the limits in human rationality (Simon, 1957), and in the managerial context (March, 1978). For this reason, the actors often need formal reference in terms of objective or framing, to compensate for uncertainties of shared-management (Bouchikhi and Kimberly, 1992).

In the second place, the rules of self-management based on the search for collective consensus do not envisage anything on the resolution of individual conflicts. In case of discord, there is not even any referee able to prevent the compartmentalization of the individuals inside the network. To reduce this problem, certain industrial districts function with external mediators who are neutral by definition.

Lastly, the self-regulation of the exchanges loses of its effectiveness with the chain ruptures and the structural holes mentioned by Burt and Ronchi (1994). Within the network, the absence of intermediary thus prevents from connecting the elements to sustain the emergence of a collective consensus. These remarks highlight the weakness and the instability structural of self-organized networks, in the absence of regulating center able to harmonize the interactions.

In this context, the network does not evolve according to a foreseeable logic of construction, reduced to the planned assembly of the autonomous elements. One may not assimilate the "whole" to the "parts". Indeed, according to Morin ${ }^{11}$ (1982), it seems that the reticular structure is not simply an aggregate of individual actions because this one has properties for himself. If the structure is not the deliberated work on a group of individuals, it is affirmed more like a mental construction adapted to the needs for abstraction and rationalization of the entities faced to their uncertainties (Daft and Weick, 1984).

Confronted with the dialectical between collaboration and conflict at different levels, the network not supervised is subjected according to Stacey (1995) to two opposite

\footnotetext{
${ }^{11}$ For Morin (1982) "the whole is more than the sum of the parts (principle disengaged well and from the remainder intuitively recognized on all macroscopic levels), since on its level not only one macro-unit emerges, but also some new qualities/properties. The whole is less than the sum of the parts (since those under the effect of the constraints resulting from the organization from the whole, lose or see inhibiting some of their qualities or properties). The whole is more than the whole, since the whole retro-acts on the parts which in their turn retro-act on the whole; in other words, the whole is more than one global reality, it is an organizational dynamism."
} 
forces: a tendency to stability by research of balance, and a tendency to instability caused by the latent disorder. In the stability register, Prigogine and Stengers (1979) insist on the mechanisms of anticipations and feed-backs which allow the network in situation of entropy to return in a global state of balance, necessary to guarantee the coherence of the collective action.

Focalized on instability, Miles and Snow (1992) denounce the idea of balance within the network. According to these authors, failures inevitably appear because of contradictions between the individuals.

For instance, the situations of competition then cause the fragmentation of the decision-making centers and the dispersal of the nodes. In the absence of centralized coordination, the room for maneuver between rival units indeed encourages them to isolate their competencies and to partition their resources. By confronting the position of Miles and Snow (1992) with that of Prigogine and Stengers (1979), we are able to affirm that the evolution of the network not supervised is subjected to stability and plasticity ${ }^{12}$ dialectical.

- At the global level, the organization must remain coherent and stable to preserve its unity. In this context, it tends to fix the behavioral rules; what results in a standardization of the functions and a high degree in the exchanges homogeneity, in order to make the organization foreseeable and controllable by the members.

- At the local level, on the contrary the organization must stay dynamic, flexible and modular. The members must adapt quickly to their specific environment with their decisional autonomy. That causes to decrease the degree of cohesion between the members.

\subsubsection{Stability: The conservation state in the network}

For Stacey (1995), when all the agents implied in the network agree to observe common rules in their behaviors, then this organization will tend to reach a situation of steady balance. Thus, the "normalization" of the exchanges rules is the first factor of stability in the self-organization. That means that the transformations within the network fit in a consensual universe, which preserves the cohesion in the collective action.

With the difference of inert objects, the networks are maintained only through the action and the change. Their identity and their invariant do not come from the permanence of the components, but from the stability of their form and their structure, despite flows of entries and exits, or despite the conflicts sources of local contradictions. So, there is to some extent a permanence of the net forms, which take shape progressively from interactions. For this reason, the situation of stability is ensured by exogenous imbalances when flows of entry counterbalance flows of exits. It also rests on endogenous disorders, when the weight of contradictions finds a point of equilibrium, or when the competitions lead to a consensus. Therefore, the convergence of particular interests

\footnotetext{
12 Plasticity is the quality of a matter to receive various forms. It is also the capacity of an individual to deconstruct a perceived unit and to restructure it in a different form. For a network, it is about a property of adaptation which confers on the structure different functions with the same elements or an identical functions with different elements.
} 
allows the network to preserve its "raison d'être": the common denominator which federates the elements in the absence of supervisor.

This phenomenon is identical to the principle of systems conservation from the framework of homeostasis ${ }^{13}$ (Durand, 1979).

But within the framework of the conservation process, some disturbances are inevitable. Let us suppose that we observe a network: it will grow, age, die or be regenerated (Larson, 1992). The principle of conservation prevents it from dying not by a simple reversibility of time (once that one is old, one does not survive while turning over to childhood), but through the creation of a descendant (Ito and Rose, 1994). The birth or the entry of new units ensures the conservation of the organization, but also constitutes a discontinuity in its course.

Indeed, the new one cannot be obtained by a simple replication of the old. In other words, if the organization remained in the same form, inside the same type of change, the process of development would reach a limiting threshold. The conservation of the organization is thus ensured by a discontinuity, source of instability, with the emergence of individuals having new characteristics. To evaluate this change, one cannot concentrate only on flows of entry and exit, but it is necessary to take into account the capacity of adaptation of the network or its degree of plasticity.

\subsubsection{Plasticity: The adjustable state in the network}

The process of homeostasis within the network with autonomous dynamics is called into question by the need for variety. The network variety is the number of configurations or states which it can cover. This variety is thus the reflection of a capacity of adaptation related to the form: plasticity. The property of variety comes primarily from the diversity of the elements which can be substitutable or complementary, multipurpose or redundant. For this reason, the variety of the network constitutes to some extent a reservoir of resources, an organizational slack, in which it can draw to ensure its balance, in order to have a certain capacity of adaptation (March and Simon 1958). Now, the networks with autonomous dynamics have a higher level of variety, compared to level necessary for their simple maintenance. Beyond this operational aspect, they thus have a reserve of resources or competencies which compensates for the functional failure of an element or the rupture of a connection.

For Durand (1979), the variety therefore allows the networks:

- to establish a good coordination between the elements;

- to find answers adapted to the disturbances coming from the environment;

- to learn from new behaviors or to innovate.

\footnotetext{
${ }^{13}$ Homeostasis expresses a complex process as feedback which acts to maintain the stationary state of a system in its morphology, and in its internal conditions, despite the external disturbances. Homeostasis is a complex process with many components; in the case of the organisms one can quote: the maintenance of the blood pressure, the internal temperature monitoring, the immunological processes, the content of vital substances.
} 
Nevertheless, this type of evolution presents two significant limits. First of all, to supervise the network, it is necessary to have a method of control whose variety is at least equal to the variety of the organization. Thus, plasticity must be supervised by methods which adapt to the pattern of trade. In this perspective, the rules of exchanges must evolve at the same rhythm than the organization, otherwise it can have a risk of disintegration. Beyond a certain threshold of inconsistency, the dissemination of the elements can indeed cause the disappearance of the network in its not supervised form (Miles and Snow, 1992).

Moreover, the principle of variety introduces a second limit. With respect to the concept of learning organization, advanced by Freedman (1992), Bourret et al. (1991) mention the following problem. If plasticity, the adaptability of the network is privileged, its storage capacity will regress in term of memory. On the contrary, if stability is privileged, the capacity of learning will decrease. The propensity of the network to change of behavior according to the results of its former experiment will be then less large. At the consequence, its capacity of adaptation will be less low.

However, it is difficult to check empirically all these considerations. Indeed, the types of evolution (state of conservation or search for variety) are too complex to be approached with the methodological tools we currently use in social sciences. For example, the cartographic method applied by Burt and Ronchi (1994) don't fit to transverse and longitudinal analyses. From photographic type, this method indicates a particular state of the structure at a given moment, favorable to identify the central positions, the mediators, the homogeneous sub-groups. In the same way, the sociogram resulting from the graph theory (Kanski, 1989) does not take into account the dynamic aspect of the network: neither of its evolution in the course of time, nor of its territorial evolution. In order to have a vision close to reality, we are then constrained to proceed to a modeling.

\subsection{Modeling: Order-disorder}

To illustrate the dynamics of a self-organized network, we chose to use the modeling software, defined by the group of research in epistemology at the "MIT Media Lab" 14 . This software called "Star Logo", indeed makes it possible to model decentralized systems, in other words, self-organized systems without pilots. With "Star Logo", it is thus possible to visualize in a clinical way, complex phenomena like the activation of a neural network, or the self-management of a colony of ants. During this data-processing experiment, we are brought to observe evolutions of forms in the absence of central regulator which illustrate the problems of dynamics, questioned in this article.

\footnotetext{
${ }^{14}$ The epistemological group of study at the MIT media Lab, has developed a modeling software about decentralized systems: Star Logo. This software is particularly suitable to create data-processing animations starting from the programming of interconnections between thousands of luminous points. For this reason, Star Logo is particularly adapted for projects in artificial intelligence which seek to simulate and to visualize phenomena of order creation in a living organism. Star Logo is a freeware software accessible on Internet at this address: http://www.media.mit.edu/ starlogo/
} 
Indeed, the programming of "Star Logo" attempts to recreate the operation of the networks with dynamics autonomous. In this program, the network is modeled by a certain number of luminous and colored points. Each one of these elements can ignite or die out, preserve its color or change color. The rule of activation of the points is thus laid down on a binary mode as in the connectionist model. In addition, this one takes account of the dynamic dimension in the interactions between the elements. For instance, a luminous point can flicker or change of color, as from the moment when all the other close points are themselves flickering or changing color. The changing state of a point is thus determined by the rules of interactions fixed at the beginning. From the moment when each element of the network is connected to other ones in a random way, and from the moment when one assigns in a random way of the different behavioral rules between the elements located randomly, one obtains all the requirements to observe the complex phenomena of self-organization.

On a local level, each element is influenced by the state of the elements which surround it. That leads it to adjust its state, by modifying or by preserving its beginning state at the origin, according to the programming rules. In return, it contributes to modify its close environment and consequently the state of the elements to which it is directly connected. This process of mutual adjustment will be propagated gradually by the set of ramifications between the points. At the end of this evolution, the network of luminous points is affected on a global level. The net configuration changes progressively from the interactions.

Two contrasted situations then occur: the evolution can proceed in a chaotic way and lead to a greater instability (Thietart and Forgues, 1993), or, on the contrary it can be stabil- ized around invariant forms, which Ruelle (1981) or Thom (1981) name small islands of rationality.

\subsubsection{Unstable and random evolution}

The chaotic tendency is observed in an alternative of the Star Logo program, in which the network is animated by retro-propagation procedures, which very quickly move away the organization from its initial point of equilibrium. The frequency of the changes develops with time to completely divert the network of its initial configuration as the two labels of Figure 2 indicate it. Even if this phenomenon is random, it has a deterministic origin (Ekeland, 1991). In reality, the rules of programming order and specifie the local behavior of each entities.

However, the chance intervenes in the fact that it is impossible to envisage the global configuration of the network, because of the recursively loops registered in the program. In the long term, those make the evolution unstable and unforeseeable. One can compare this random evolution in the search of plasticity evoked previously within the framework of the social and business networks.

\subsubsection{Stable and ordered evolution}

Starting from a new biological modeling developed by the team of "Star Logo", we note that other rules of local interactions can cause the emergence of stable and regular collective forms. 


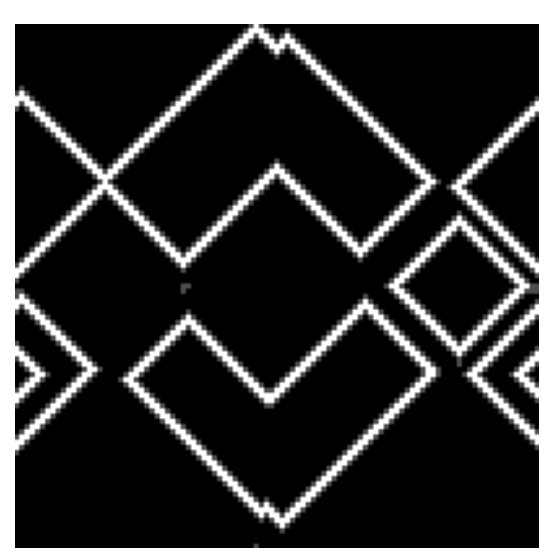

Stable and regular form

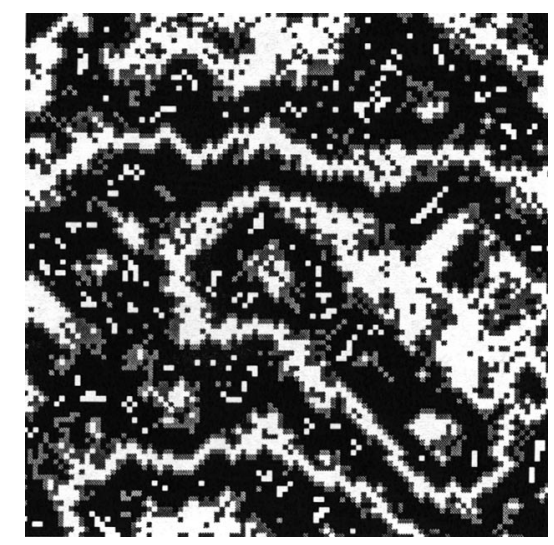

complex and irregular form (after several iterations)

Fig. 2. The search for plasticity.

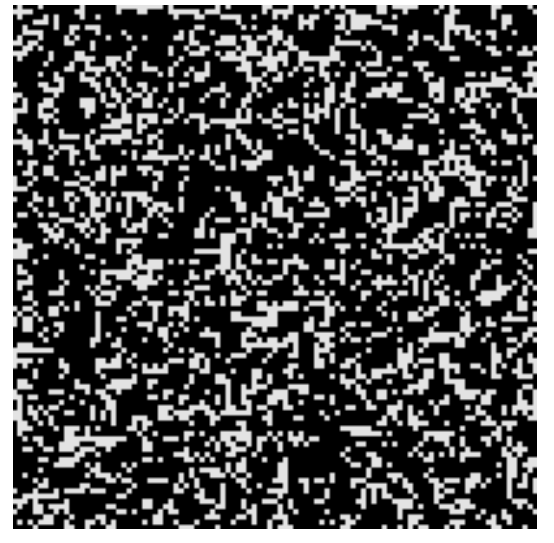

Complex and scattered form

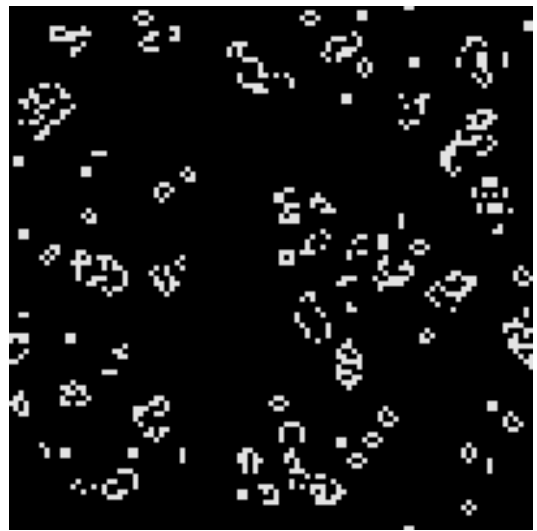

$\rightarrow$ stable and regular form

(after several iterations)

Fig. 3. The search for stability.

In this program, each element can be regarded as alive or dead, i.e. luminous or extinct. Thus, a surviving element can disappear either under the effect of an excessive isolation, or under the effect of a too great proximity with the others. It remains alive as long as two of these immediate neighbors are it also. In the opposite, it can disappear when more than three alive elements are connected to him.

Lastly, it has the possibility of "resurrect" if it is strictly connected to three surviving elements. Starting from these very basic rules, one attends the emergence of complex collective forms which are stabilized after several iterations: initial form A gives rise to the final form $\mathrm{B}$, which becomes in its turn the initial form for $\mathrm{C}$ and so on. This 
dynamics presented on Figure 3 is identical to the search of stability evoked in the social or business networks corpus.

\section{Conclusion}

This theoretical framework clarified several processes of evolutions on the self-organized networks. In the absence of pilot, these organizations evolve in regard to the interactions between the units, either towards a greater flexibility within an increasingly divided configuration, or to a search for greater stability by the formation of pole and subnetworks. But, in the business area, it is very difficult to observe phenomena identical to those which are proposed by modeling. Indeed, the corporate networks or the social networks of actors evolve permanently in their contours, in the nature of the relations and even in the rules of exchanges, so that it is "impossible", in the current state of the investigation techniques, to obtain simultaneously a local and global vision of the transformations process. Despite this lack of method, the network with autonomous dynamics is an organization still described and studied in management sciences.

Let us take the example of the industrial districts with the case of the shoe in Italy describes by Neuschwander (1991). In an Italian village, there is a set of small companies specialized in this manufacturing industry. They all are substitutable by their size and their competencies; their mode of management is based on the clan. In this context, each year, an international bid set these companies to competition.

By the result of the bid, a company is detached, but, because of its limited output, it is obliged to subcontract with other SME. A structure of temporary alliances is then founded spontaneously until the following year, where a new clan replaces the principal, which implies a new change in the organization. This principle characterizes the operation of the self-organized network in which each member has the capacity to be pilot without being able to impose its authority in a permanent way to the other members. In this manner, this type of network has the advantage of preserving the autonomy of the members and of conferring to them flexibility with creativity and learning capacities.

In the light of this example, we are able to say that the proximity of the individuals within the clan mitigates the absence of pilot to coordinate the tasks and to arbitrate the conflicts. These elements of stability facilitate the mutual adjustments to adapt outputs to the market (Inzerilli, 1990). So the plasticity of the districts remains very significant, because of the barriers at the entry and the exit. So, it does not involve necessarily the split of the structures as modeling suggests it.

In the same way, if we consider the companies governed by self-management (Bouchikhi and Kimberly, 1992), some exogenous and endogenous constraints force to harmonize the responsibilities around dominant characters (Mack and Schoch, 1992). Initially, the play of the shareholders and the competitors obliges the adoption of accounting and managerial standards in order to compare with other firms from the same sector. This constraint is difficult to reconcile with the absence of pilot at the head of the firm. In the second place, the internal rivalries require a hierarchical conciliation that the tacit rules or the habits are not always enough to replace (Assens, 1998). 
According to these examples, we find temporary or in a permanent way, industrial engineering close to the modeling: absence of center or multi-polarity authority, relational net process of emergence, regulation by the individual interactions. Under these conditions, modeling with the software "Star Logo" provides a framework to understand and anticipate the mutation of the business networks with autonomous dynamics, in three directions:

- stability to the detriment of plasticity, with the permanence of an order related to the power concentration around one or more entities inside the network;

- plasticity to the detriment of stability with the complete split of the organization and the dissemination of the decision-making centers on a market;

- the alternation of change and equilibrium cycles, to the image of the industrial districts and the organizations based on self-management with the presence of one or more temporary pilots.

Other research will have to be led to highlight the sequence of these structuring processes to several levels, by the ethnographic or sociological observation of the relationship between the actors, by the economic survey of the transactions and the financial participation, and by the industrial analysis of the sector ramifications.

\section{References}

Amar G. (1993) Qu'est-ce qui n'est pas un réseau ?, Flux, No. 13-14, pp. 56-58.

Assens C., Baroncelli A., Froehlicher T. (2000) Le pilotage des réseaux intra-organisationnels : une approche relationnelle et conventionnaliste des modes de coordination. In: Actes du $9^{e}$ congrès de l'Association Internationale de Management Stratégique (CD-Rom), ERFI, Montpellier.

Assens C. (1998) La dynamique des complémentarités et des conflits dans un réseau d'entreprises. Thèse de doctorat nouveau régime, Université Paris-Dauphine, $244 \mathrm{p}$.

Assens C. (1997) Réseau neuronal et réseau d'entreprises, Revue Française de Gestion, No. 113, pp. 5-13.

Assens C. (1996) Du modèle bureaucratique au modèle organique, Flux, No. 23, pp. 38-42.

Astley W.G., Zajac E.J. (1991) Intraorganizational power and organizational design: reconciling rational and coalitional models of organization, Organization Science, 2, pp. 399-413.

Atlan H. (1979) Entre le cristal et la fumée. Éditions du Seuil, Paris.

Aurifeille J.M. (1994) Réseaux de neurones et analyses de données en Marketing : intérêts, limites et perspectives. In: Actes du colloque sur la recherche neuronale en Sciences Economiques et de Gestion, Saint Nazaire, pp. 3-26.

Baker W.E. (1990) Market networks and corporate behaviour, American Journal of Sociologie, No. 3, pp. 589-625.

Bartlett C., Ghoshal S. (1993) Beyond the M-form: toward a managerial theory of the firm, Strategic Management Journal, 14, pp. 23-46.

Bouchikhi H. (1991) Structuration des organisations : concepts constructivistes et étude de cas. Economica, Paris.

Bouchikhi H., Kimberly J. (1992) Le management « bureauganique » : ou comment réconcilier le clan avec la bureaucratie, Gérer et Comprendre, No. 29, pp. 5-16.

Bouchon-Meunier B. (1993) La logique floue. Que-sais-je, Presses Universitaires de France. 
Bourret P., Reggia J., Samuelides M. (1991) Réseaux neuronaux : une approche connexionniste de l'intelligence artificielle. Tekna, Toulouse.

Boyd B. (1990) Corporate linkages and organizational environment: a test of the resource dependence model, Strategic Management Journal, 11, pp. 419-430.

Bressant A., Distler C., Nicolaidis K. (1989) Vers une économie de réseau, Politique Industrielle, hiver, pp. 155-168.

Broustail J. (1992a) De l'histoire à l'identité d'entreprise, quelques cas: Hachette, Rhône Poulenc, Indosuez, la Compagnie Générale des Eaux, Entreprises et Histoire, No. 1, pp. 91-100.

Broustail J. (1992b) Les entreprises ont-elles besoin d'une histoire ?, Entreprises et Histoire, No. 1, pp. 101-111.

Burkhardt M.E., Brass D.J. (1990) Changing patterns of change: the effects of a change in technology on social network structure and power, Administrative Science Quarterly, 35, pp. 104-127.

Burt R.S, Ronchi D. (1994) Measuring a large network quickly, Social Networks, 6, pp. 91-135.

Butera F. (1991) La métamorphose de l'organisation : du château au réseau. Éditions d'Organisation, Paris.

Camuffo A., Costa G. (1993) Strategic human resource management - Italian style, Sloan Management Review, hiver, pp. 59-67.

Chalmers A.F. (1987) Qu'est-ce que la science? Éditions la Découverte, Paris.

Chandler A. (1962) Strategy and structure: chapters in the history of the American industrial enterprise, MIT press.

Changeux J.P. (1983) L'homme neuronal. Éditions Fayard, Paris.

Crozier M., Friedberg E. (1977), L'acteur et le système. Éditions du Seuil, Paris.

D'Iribarne P. (1989) La logique de l'honneur. Éditions du Seuil, Paris.

Daft R.L., Lewin A.Y. (1993) Where are the theories for the "new" organizational forms? an editorial essay, Organization Science, 4, pp. 1-6.

Daft R.L., Weick K.E. (1984) Toward a model of organizations as interpretation systems, Academy of Management Review, 9, pp. 284-295.

Darwin C. (1949) The origin of species. Modern Library, New York.

Davalo E., Naim P. (1989) Des réseaux de neurones. Eyrolles, Paris.

Dörner D. (1989) La logique de l'échec. Flammarion, Paris.

Drazin R., Sandelands L. (1992) Autogenesis: a perspective on the process of organizing, Organization Science, 3, pp. 230-249.

Durand D. (1979) La systémique. Presses Universitaires de France, Paris.

Eisenhardt K.M., Zbaracki M.J. (1992) Strategic decision making, Strategic Management Journal, 13, pp. 17-37.

Ekeland I. (1984) Le calcul, l'imprévu : les figures du temps de Kepler à Thom. Éditions du Seuil, Paris.

Ekeland I. (1991) Au hasard : la chance, la science et le monde. Éditions du Seuil, Paris.

Fayol H. (1949) General and industrial management. Pitman, New York.

Freedman D.H (1992) Is management still a science?, Harvard Business Review, 3, pp. 26-38.

Fridenson P. (1993) Quand la gestion entre dans l'histoire, Revue Française de Gestion, No. 96, pp. 69-77.

Gerlach M.L. (1992) The Japanese corporate network: a blockmodel analysis, Administrative Science Quarterly, 37, pp. 105-139. 
Glick H.W., Huber G.P., Miller C.C., Doty D.H., Sutcliffe K.M. (1990) Studying changes in organizational design and effectiveness: retrospective event histories and periodic assessments, Organization Science, 1, pp. 293-312.

Gomez P., Probst J.B. (1987) Pour une approche interactive du management, L'information, No. 89.

Granovetter M.S. (1985) Economic action and social structure: the problem of embeddedness, American Journal of Sociology, 91, pp. 481-510.

Hannan M.T., Freeman J. (1977) The population ecology of organizations, American Journal of Sociology, 82, pp. 929-964.

Hanson J.R., Krackhardt D. (1993) Informal networks: the company behind the chart, Harvard Business Review, pp. 105-111.

Hebb D.O. (1949) The organization of behavior: a neuropsychological theory. John Wiley \& Sons, New York.

Inzerilli G. (1990) The Italian alternative: flexible organization and social management, International Studies of Management and Organization, 20, pp. 6-21.

Ito K., Rose E.L. (1994) The genealogical structure of Japanese firms: parent-subsidiary relationships, Strategic Management Journal, 15, pp. 35-51.

Jarillo J.C. (1988) On strategic networks, Strategic Management Journal, 9, pp. 31-41.

Kansky K. (1989) Measures of network structure, Flux, No. 0, pp. 93-121.

Kennedy C. (1992) A.B.B: model merger for the new Europe, Long Range Planning, 25, pp. 10-17.

Kimberly J., Bouchikhi H. (1991) The dynamics of organizational development and change: how the past shapes the present and constrains the future, Organization Science, 6, pp. 9-18.

Kohonen T. (1988) Self-organization and associative memory. 2nd edn., Springer-Verlag, Berlin.

Larson A. (1992) Network dyads in entrepreneurial setting: a study of the governance of exchange relationships, Administrative Science Quarterly, 37, pp. 76-104.

Le Moigne J.L. (1989) La mémoire du réseau tout s'écoule... et pourtant... Cahier du GRASCE, No. 89-05.

Le Moigne J.L., Jameux C. (1990) Reseaux locaux et formes nouvelles d'organisation, Cahier du GRASCE, No. 90-14.

Lomi A. (1999) L'étude relationnelle de l'organisation sur différents plans de l'analyse. In: Lomi A. (Ed.), L'analyse relationnelle des organisations. L'Harmatthan, Paris, pp. 23-57.

Lorenzoni G., Baden fuller C. (1993) Creating a strategic center to manage a web of partners, California Management Review, 37, pp. 146-163.

Lorigny J. (1992) Les systèmes autonomes : relation aléatoire et sciences de l'esprit. Dunod, Paris.

Lussato B. (1992) Introduction critique aux théories d'organisation. Dunod, Paris.

Mack M., Schoch C. (1992) L'open space d'Accor, Management et Conjoncture Sociale, No. 387, pp. 13-17.

March J. (1978) Bounded rationality, ambiguity and the engineering of choice, The Bell Journal of Economics, 9, pp. 587-608.

March J., Simon H. (1958) Les organisations. Dunod, Paris.

Miles R., Snow C. (1986) Organizations: new concepts for new forms, California Management Review, 27, pp. 62-73. 
Miles R., Snow C. (1992) Causes of failure in network organizations, California Management Review, 34, pp. 53-72.

Monod J. (1970) Le hasard et la nécessité. Éditions du Seuil, Paris.

Morin E. (1977) La méthode (la nature de la nature). Éditions du Seuil, Paris.

Morin E. (1982) Science avec conscience. Fayard, Paris.

Morin E. (1985) La méthode (la vie de la vie). Éditions du Seuil, Paris.

Neuschwander C. (1991) L'acteur et le changement : essai sur les réseaux. Éditions du Seuil, Paris.

Nonaka I. (1988) Creating organizational order out of chaos: self renewal in Japanese firms, Strategy \& Organization, pp. 57-73.

Osborn R.N., Hagedoorn J. (1997) The institutionalization and evolutionary dynamics of interorganizational alliances and networks, Academy of Management Journal, 40, pp. 261-278.

Perez J.C. (1990) La révolution des ordinateurs neuronaux. Hermes, Paris.

Pettigrew A.M. (1990) Longitudinal field research on change: theory and practice, Organization Science, 1, pp. 267-292.

Pfeffer J., Salancik C.A. (1978) The external control of organization. Harper and Row, New York.

Popper K. (1989) La quête inachevée. Calmann Levy, Paris.

Prigogine I., Stengers I. (1979) La nouvelle alliance. Gallimard, Paris.

Raub W., Weesie J. (1990) Reputation and efficiency in social interaction: an example of networks effect, American Journal of Sociology 96 (3), pp. 626-654.

Ruelle D. (1981) Hasard et déterminisme le problème de la prédictibilité, Traverses, No. 23.

Semler R. (1990) Une entreprise sans chefs, Harvard l'Expansion, No. 58, pp. 44-54.

Simon H. (1957) Models of man, social and rational. Wiley, New York.

Stacey R.D. (1995) The science of complexity: an alternative perspective for strategic change process, Strategic Management Journal, 16, pp. 477-495.

Susman G.I., Evered R.D. (1978) An assesment of the scientific merits of action research, Administrative Science Quarterly, 23, pp. 582-603.

Taylor F.W. (1916) Scientific management. Harper and Row, New York.

Thietart R.A., Forgues B. (1993) Chaos theory and organization, Organization Science, 6, pp. 19-31.

Thom R. (1981) Halte au hasard, silence au bruit, Supra, pp. 61-78.

Thorelli H.B. (1986) Networks: between markets and hierarchies, Strategic Management Journal, 7, pp. 37-51.

Von Neumann J., Morgerstern O. (1947) Theory of games and economic behavior. Princeton University Press, Princeton.

Watzlawick P., Helmik Beavin J., Jackson D.D. (1972) Une logique de la communication. Éditions du Seuil, Paris.

Watzlawick P., Weakland J., Fisch R. (1975) Changements paradoxes et psychotérapie. Éditions du Seuil, Paris.

Weisbuch G. (1989) Dynamique des systèmes complexes : une introduction aux réseaux d'automates. InterEditions, Paris.

Weiss D. (1994) Nouvelles formes d'entreprises et relations de travail, Revue Française de Gestion, No. 96, pp. 95-103.

Williamson O.E. (1983) Markets and hierarchies. The Free Press, New York. 